\title{
Acute otitis media in children
}

This article was published in the following Dove Press journal:

International Journal of General Medicine

I June 201 I

Number of times this article has been viewed

\section{Jacques Cherpillod}

Ear, Nose and Throat Department, Childrens' University Hospital, Lausanne, Switzerland

Date of preparation: 6th March 20II Conflict of interest: None declared
Clinical question: What is the best treatment for acute otitis media in children?

Results: Watchful waiting, followed by amoxicillin treatment, if necessary, is the best first-line treatment for acute otitis media in children aged six months or older.

Keywords: acute otitis media, antibiotics, watchful waiting

Definition: Acute otitis media (AOM) is an acute bacterial infection of the middle ear fluid. It must be clearly distinguished from middle ear effusion, which is noninfected middle ear fluid.

Etiology: Mostly Streptococcus pneumoniae, Haemophilus influenzae, and Moraxella catarrhalis. Since the introduction of the PCV7 vaccine, there has been an increase in $H$. influenzae and nonvaccine serotypes of S. pneumoniae.

Incidence: AOM is the most frequent diagnosis in sick children visiting the physician's office. The incidence is maximal at the age of 6-24 months and decreases with age. It is infrequent in school-aged children.

Economics: In 2000, it was estimated that AOM accounted for $\$ 5$ billion of annual expenditure in the US.

Level of evidence: Systematic reviews, meta-analyses, randomized controlled trials. Because this pathology is very frequent, there are hundreds of papers (from 2001 to current, 260 reviews, 23 meta-analyses, 31 randomized controlled trials) and it is impossible to give results and a reference for each individual paper.

Search sources: PubMed, Cochrane Library, UptoDate (2001 to current)

Outcomes: Time to resolution of symptoms, avoidance of recurrent AOM, avoidance of middle ear effusion, avoidance of other complications.

Consumer summary: AOM in children is the most frequent reason for visiting a physician. It is self-limiting in most cases, and its complications are rare. There is good evidence that watchful waiting for two days followed by antibiotic treatment if necessary is the best treatment. No other treatments help, except for the usual pain remedies.

\section{The evidence}

Correspondence: Jacques Cherpillod Ear, Nose and Throat Department, Childrens' University Hospital, Montétan 18, Lausanne, Switzerland

$\mathrm{Tel}+4$ I 2 I 3207929

Fax +4I 2I 3II0084

Email jacques.cherpillod@chuv.ch

\section{Antimicrobial treatment versus watchful waiting?}

In children aged six months to 12 years, 7-14 days of antibiotic treatment compared with placebo or watchful waiting provided a more favorable short-term clinical course, but a higher incidence of diarrhea. The treatment effect was small. 
There was no difference in disease complications, development of persistent middle ear effusion, or recurrence of AOM, ${ }^{1-11}$ and a very slight difference for the risk of mastoiditis (0.7 versus $2.0 / 10000) .{ }^{10}$

Children younger than two years of age with bilateral AOM and children with AOM and otorrhea have a higher risk of an extended course of disease. ${ }^{2}$ There is no statistically significant effect of antibiotic therapy in preventing development of asymptomatic middle ear effusion at one month. ${ }^{12}$

\section{Choice of antimicrobial treatment?}

There are no significant differences in antibiotic effectiveness, except in a few individual studies. Almost all of the studies conclude that amoxicillin is the first-choice antibiotic, except in children with penicillin allergy or those who previously did not improve after a course of amoxicillin. See below for choice in these situations.

The doses for amoxicillin and amoxicillin-clavulanate require consideration of the geographic area where patients are treated. A high dose of amoxicillin or amoxicillinclavulanate or three doses of ceftriaxone are necessary for recurrent or nonresponsive AOM because they are often caused by intermediate-resistant $S$. pneumoniae. ${ }^{13,14}$

\section{Duration of antimicrobial treatment?}

Risk of treatment failure is slightly higher with short courses of antibiotics ( $<7$ days versus $\geq 7$ days) one month after initiation of therapy (difference of 3\% between groups) except for ceftriaxone and azithromycin. ${ }^{15,16}$

\section{Other treatments?}

The 7-valent PCV administered during infancy has marginal beneficial effects. Administering 7-valent PCV in older children with a history of AOM appears to have no benefit in preventing further episodes. ${ }^{17}$ In children $1-7$ years of age this does not change the rate of recurrent AOM. ${ }^{18}$ It is not clear if administration of influenza vaccine to children does or does not reduce occurrence of AOM. ${ }^{19-21}$ Probiotics do not prevent the occurrence of AOM in children aged 10 months to six years, but might help in the first year of life..$^{22,23}$ Echinacea purpurea during colds and manipulative osteopathic treatment do not prevent the occurrence of AOM in children aged 1-5 years. ${ }^{2}$ Decongestants and antihistamines are useless. ${ }^{25}$ Ventilation tube insertion leads to a mean reduction of 1.5 episodes of acute otitis media in the first six months. ${ }^{26}$ Adenoidectomy does not prevent recurrent AOM. ${ }^{27}$

\section{The practice}

\section{Potential pitfalls}

It is important to be trained in otoscopy and have a good otoscope, preferably a pneumatic otoscope.

\section{Management}

AOM is usually managed by nonspecialists. Indications for specialist referral are given below.

\section{Assessment}

It is important to recognize that AOM is frequently overdiagnosed. Most symptoms described by parents correlate poorly with AOM and may simply result from a cold. In terms of otoscopic signs, bulging, a cloudy aspect, an immobile eardrum on pneumatic otoscopy, and redness (from best to worst) have a good association with AOM. Look for risk factors, i.e. day care in large groups, use of a pacifier, feeding in a supine position, tobacco smoke and air pollution, bottle feeding, family history, and underlying disease (eg, cleft palate, Down syndrome, immunity problems).

\section{Treatment}

Treat every child younger than six months, children six months to two years with bilateral AOM, and children with otorrhea with antibiotics. Give pain remedies and schedule an appointment or at least a telephone follow-up in 48-72 hours for all other children with AOM. Treat them with antibiotics only if they do not improve.

The first-choice antibiotic is amoxicillin $50 \mathrm{mg} / \mathrm{kg} /$ day. In countries with a high proportion of intermediate-resistant $S$. pneumoniae, give $90 \mathrm{mg} / \mathrm{kg} /$ day (maximum $3 \mathrm{~g} / \mathrm{day}$ ).

For children who have been treated in the previous 30 days, those with concurrent conjunctivitis, and treatment failure after 48-72 hours, choose amoxicillin-clavulanate $90 \mathrm{mg} / \mathrm{kg} /$ day in two divided doses. Treat children older than two years for five days and children two years or younger for 10 days.

In the event of penicillin allergy with non-type 1 reactions, give cefdinir $14 \mathrm{mg} / \mathrm{kg}$ /day (maximum $600 \mathrm{mg} /$ day), cefpodoxime $10 \mathrm{mg} / \mathrm{kg} /$ day (maximum $800 \mathrm{mg} /$ day), or cefuroxime $30 \mathrm{mg} / \mathrm{kg}$ /day (maximum $1 \mathrm{~g} /$ day), all in two divided doses. With type 1 reactions, give a macrolide, i.e. azithromycin $10 \mathrm{mg} / \mathrm{kg} /$ day in one dose (maximum $500 \mathrm{mg} /$ day) for three days or clarithromycin $15 \mathrm{mg} / \mathrm{kg} /$ day (maximum $1 \mathrm{~g} /$ day) for five days. However, none of these agents can eradicate penicillin-resistant $S$. pneumoniae. 
An alternative treatment is a single intramuscular dose of ceftriaxone $50 \mathrm{mg} / \mathrm{kg}$. If there is no improvement after 48 hours, a second dose and even a third dose can be administered.

Give ibuprofen $10 \mathrm{mg} / \mathrm{kg}$ three times per day. Check for disappearance of middle ear effusion after three months.

\section{Indications for specialist referral}

Contact an Ear, Nose and Throat specialist for any child with AOM and signs of mastoiditis, facial palsy, sudden vertigo, or sudden important hearing loss. Routine referral to an Ear, Nose and Throat specialist is advised if middle ear effusion has not disappeared after three months.

\section{Further reading}

Coker TR, Chan LS, Newberry SJ, et al. Diagnosis, microbial epidemiology, and antibiotic treatment of acute otitis media in children: A systematic review. JAMA. 2010;304(19):2161-9.

\section{References}

1. Coker TR, Chan LS, Newberry SJ, et al. Diagnosis, microbial epidemiology, and antibiotic treatment of acute otitis media in children: A systematic review. JAMA. 2010;304(19):2161-2169.

2. Rovers MM, Glasziou P, Appelman CL, et al. Antibiotics for acute otitis media: A meta-analysis with individual patient data. Lancet. 2006;368(9545):1429-1435.

3. Gunasekera H, Morris PS, McIntyre P, Craig JC. Management of children with otitis media: A summary of evidence from recent systematic reviews. $J$ Paediatr Child Health. 2009;45(10):554-562.

4. Vouloumanou EK, Karageorgopoulos DE, Kazantzi MS, Kapaskelis AM, Falagas ME. Antibiotics versus placebo or watchful waiting for acute otitis media: A meta-analysis of randomized controlled trials. J Antimicrob Chemother. 2009;64(1):16-24.

5. Takata, GS, Chan, LS, Shekelle P, et al. Evidence assessment of management of acute otitis media: I. The role of antibiotics in treatment of uncomplicated acute otitis media. Pediatrics. 2001;108(2):239-247.

6. Glasziou PP, Del Mar CB, Sanders SL, Hayem M. Antibiotics for acute otitis media in children. Cochrane Database Syst Rev. 2004;1:CD000219.

7. Le Saux N, Gaboury I, Baird M, et al. A randomized, double-blind, placebo-controlled noninferiority trial of amoxicillin for clinically diagnosed acute otitis media in children 6 months to 5 years of age. CMAJ. 2005;172(3):335-341.

8. McCormick DP, Chonmaitree T, Pittman C, et al. Nonsevere acute otitis media: A clinical trial comparing outcomes of watchful waiting versus immediate antibiotic treatment. Pediatrics. 2005;115(6):1455-1465.

9. Hoberman A, Paradise JL, Rockette HE, et al. Treatment of acute otitis media in children under 2 years of age. $N$ Engl J Med. 2011;364(2):105-115.
10. Keith T, Saxena S, Murray J, Sharland M. Risk-benefit analysis of restricting antimicrobial prescribing in children: What do we really know? Curr Opin Infect Dis. 2010;23(3):242-248.

11. Vergison A, Dagan R, Arguedas A, et al. Otitis media and its consequences: Beyond the earache. Lancet Infect Dis. 2010;10(3):195-203.

12. Koopman L, Hoes AW, Glasziou PP, et al. Antibiotic therapy to prevent the development of asymptomatic middle ear effusion in children with acute otitis media: A meta-analysis of individual patient data. Arch Otolaryngol Head Neck Surg. 2008;134(2):128-132.

13. Pelton SI, Leibovitz E. Recent advances in otitis media. Pediatr Infect Dis J. 2009;28(10 Suppl):S133-S137.

14. Leibovitz E. The challenge of recalcitrant acute otitis media: Pathogens, resistance, and treatment strategy. Pediatr Infect Dis J. 2007;26(10 Suppl):S8-S11.

15. Kozyrskyj A, Klassen TP, Moffatt M, Harvey K. Short-course antibiotics for acute otitis media. Cochrane Database Syst Rev. 2010;(9):CD001095.

16. Gulani A, Sachdev HP, Qazi SA. Efficacy of short course ( $<4$ days) of antibiotics for treatment of acute otitis media in children: A systematic review of randomized controlled trials. Indian Pediatr. 2010;47(1):74-87.

17. Jansen AG, Hak E, Veenhoven RH, Damoiseaux RA, Schilder AG, Sanders EA. Pneumococcal conjugate vaccines for preventing otitis media. Cochrane Database Syst Rev. 2009;(2):CD001480.

18. Brouwer CN, Maillé AR, Rovers MM, et al. Effect of pneumococcal vaccination on quality of life in children with recurrent acute otitis media: A randomized, controlled trial. Pediatrics. 2005;115(2):273-276.

19. Hoberman A, Greenberg DP, Paradise JL, et al. Effectiveness of inactivated influenza vaccine in preventing acute otitis media in young children: A randomized controlled trial. JAMA. 2003;290(12):1608-1616.

20. Jansen AG, Sanders EA, Hoes AW, van Loon AM, Hak E. Effects of influenza plus pneumococcal conjugate vaccination versus influenza vaccination alone in preventing respiratory tract infections in children: A randomized, double-blind, placebo-controlled trial. J Pediatr. 2008;153(6):764-770.

21. Marchisio P, Esposito S, Bianchini S, et al. Efficacy of injectable trivalent virosomal-adjuvanted inactivated influenza vaccine in preventing acute otitis media in children with recurrent complicated or noncomplicated acute otitis media. Pediatr Infect Dis J. 2009;28(10):855-859.

22. Hatakka K, Blomgren K, Pohjavuori S, et al. Treatment of acute otitis media with probiotics in otitis-prone children - a double-blind, placebocontrolled randomised study. Clin Nutr. 2007;26(3):314-321.

23. Rautava S, Salminen S, Isolauri E. Specific probiotics in reducing the risk of acute infections in infancy - a randomised, double-blind, placebo-controlled study. Br J Nutr. 2009;101(11):1722-1726.

24. Wahl RA, Aldous MB, Worden KA, Grant KL. Echinacea purpurea and osteopathic manipulative treatment in children with recurrent otitis media: A randomized controlled trial. BMC Complement Altern Med. 2008;8:56.

25. Coleman C, Moore M. Decongestants and antihistamines for acute otitis media in children. Cochrane Database Syst Rev. 2008;(3):CD001727.

26. McDonald S, Langton Hewer CD, Nunez DA. Grommets (ventilation tubes) for recurrent acute otitis media in children. Cochrane Database Syst Rev. 2008;(4):CD004741.

27. van den Aardweg MT, Schilder AG, Herkert E, Boonacker CW, Rovers MM. Adenoidectomy for otitis media in children. Cochrane Database Syst Rev. 2010;(1):CD00781.
International Journal of General Medicine

\section{Publish your work in this journal}

The International Journal of General Medicine is an international, peer-reviewed open-access journal that focuses on general and internal medicine, pathogenesis, epidemiology, diagnosis, monitoring and treatment protocols. The journal is characterized by the rapid reporting of reviews, original research and clinical studies across all disease areas.

\section{Dovepress}

A key focus is the elucidation of disease processes and management protocols resulting in improved outcomes for the patient.The manuscript management system is completely online and includes a very quick and fair peer-review system. Visit http://www.dovepress.com/ testimonials.php to read real quotes from published authors. 